\title{
ASBESTOS IN POLAND: OCCUPATIONAL HEALTH PROBLEMS
}

\section{NEONILA SZESZENIA-DĄBROWSKA, BEATA ŚWIĄTKOWSKA, ZUZANNA SZUBERT, and URSZULA WILCZYŃSKA}

Nofer Institute of Occupational Medicine, Łódź, Poland

Department of Occupational and Environmental Epidemiology

\begin{abstract}
The presentation addresses current problems of health risk and health effects associated with exposure to asbestos, including data on historical exposure and on currently valid occupational exposure limits. The quantity and types of the raw material used for the production of various asbestos products have also been discussed in relation to the particular types of asbestos-induced occupational diseases. The authors describe the medical care system for former asbestos workers and those currently exposed during removal of asbestos-containing products. The national system for medical certification of occupational asbestos-related diseases and the compensation procedure have been outlined as well. According to the parliamentary Act of 1997, importing, manufacture and sale of asbestos and asbestos-containing materials are prohibited in Poland. Thus, the assessment of asbestos exposure and the monitoring of health conditions of workers at asbestos-processing plants have become irrelevant. However, the delayed health effects attributable to past exposure continue to be the matter of concern for public health. Likewise, the environmental pollution from asbestos waste landfills in the vicinity of asbestos-processing plants (where high levels of asbestos fibre in ambient air have been recorded) will continue to be a serious public health problem. Presently, two programmes aimed at minimising the adverse effects of asbestos on population health are underway. One of them is the governmental programme for "Elimination of asbestos and asbestos-containing products used in Poland, 2002-2032". The programme was updated in 2009 to cover the workers contracted to perform demolition works and provide protective covers to asbestos waste landfills. This will be the exposed group who need prophylactic health care. The other is a programme of prophylactic examinations for former asbestos workers and is referred to as the AMIANTUS programme. Both programmes have been briefly described.
\end{abstract}

Key words:

Asbestos consumption, Occupational exposure, Health care, Occupational asbestos-related diseases, Compensation system

\section{INTRODUCTION}

Asbestos, a naturally occurring fibrous mineral that is commonly encountered in the environment, belongs to the most serious health hazards. Despite the fact that the use of asbestos has been prohibited in many countries, both the specific biological activity and the health effects of exposure make asbestos an important public health problem worldwide.

Poland has no asbestos deposits; however, asbestos manufacturing in Poland started as early as in 1907, when the first asbestos-cement plant was founded. Since 1945, a total of 2 million tonnes raw material had been imported to Poland. This was mostly chrysotile from the former Soviet Union. A large-scale commercial application of asbestos in the construction industry began in the 1960s, when four big asbestos-cement plants started operating. Chrysotile prevailed, but until the mid 1980s, crocidolite and small amounts of amosite were also used, mainly to manufacture pressure pipes. In the manufacture of asbestos-cement products, the total consumption of asbestos since 1960s to 1998 is estimated to be about 1.5 million tonnes;

This work was performed under the project "Assessment of exposure and risk of occupational diseases among former asbestos workers" (IMP 10.1).

Received: February 28, 2011. Accepted: March 23, 2011.

Address reprint requests to N. Szeszenia-Dąbrowska, Department of Occupational and Environmental Epidemiology, Nofer Institute of Occupational Medicine, św. Teresy 8, 91-348 Łódź, Poland (e-mail: wies@imp.lodz.pl). 
including about 86000 tonnes of crocidolite and about 8500 tonnes of amosite. Between 1959 and 1984, about 72\% (ca. 60000 tonnes) of the total volume of crocidolite used to produce construction materials in Poland was consumed by a single plant manufacturing large-diameter pressure pipes. Since 1985, crocidolite is no longer used in Poland [1].

The total quantity of asbestos products in Poland is estimated to be approximately 15.5 million tonnes, the 14.9 million tonnes of which are asbestos-cement boards (1351.5 million $\mathrm{m}^{2}$ ). The remaining 600000 tonnes are piping and other asbestos-cement products. In Poland, about $85 \%$ of asbestos is located in construction materials and products. It should be stressed that large amounts of asbestos-cement products remain in the environment and are still in use; they constitute a source of severe health hazard to the inhabitants. The highest accumulation of asbestos products can be noted in the rural areas; it is three times as high as in the urban areas [2].

\section{ASBESTOS EXPOSURE AND OCCUPATIONAL HYGIENE STANDARDS}

The earliest available information about asbestos air concentration at a plant manufacturing asbestos yarns and fabrics dates back to 1949. At that time, the maximum admissible number of asbestos particles was 180 million per $1 \mathrm{~m}^{3}$ of air. The measurements performed in the plant had revealed values from two to 24 times exceeding this limit. In 1954, the maximum admissible concentration (MAC) for asbestos dust in workplace was $2 \mathrm{mg} / \mathrm{m}^{3}$ (Table 1). In 1950s, asbestos concentration measured in some workplaces was found to exceed that limit value more than 50 -fold. The workers at asbestos plants where the production had started shortly after World War II reported that the asbestos dust at the shop floor resembled a snowfall. Later on, the provision of machine casings and closed air circulation systems helped to significantly reduce the concentration levels. Nevertheless, in 1970s, asbestos dust concentrations at some plant departments (e.g., spinning dept.) were still ca. four times higher than the MAC value. At many work posts, asbestos dust concentration would range from 1 to $25 \mathrm{mg} / \mathrm{m}^{3}$. Average maximum concentrations of airborne asbestos fibres recorded in 1980s at the plants manufacturing asbestos yarns and fabrics ranged from 7 to 8.3 fibres $/ \mathrm{cm}^{3}[3]$.

Routine measurements of respirable fibre concentrations in $1 \mathrm{~cm}^{3}$ of workplace air were initiated as late as in the 1980s, when the occupational hygiene standard that covered this specific parameter came into force. Standard

Table 1. Maximum admissible concentration (MAC) values for dusts containing mineral fibres in Poland (time-weighted average for 8-h work shift)

\begin{tabular}{ccccc}
\hline & \multicolumn{2}{c}{$\begin{array}{c}\text { Dust containing chrysotile and other fibres (except } \\
\text { crocidolite) }\end{array}$} & \multicolumn{2}{c}{$\begin{array}{c}\text { Dust containing crocidolite } \\
\text { and antigorite }\end{array}$} \\
\cline { 2 - 5 } Year & \multicolumn{2}{c}{$\begin{array}{c}\text { fibres } \\
\text { diameter }<3 \mu \mathrm{m} \\
\text { length }>5 \mu \mathrm{m} \\
\left(\mathrm{f} / \mathrm{cm}^{3}\right)\end{array}$} & total dust $\left(\mathrm{mg} / \mathrm{m}^{3}\right)$ & $\begin{array}{c}\text { fibres } \\
\text { diameter }<3 \mu \mathrm{m} \\
\text { length }>5 \mu \mathrm{m} \\
\left(\mathrm{f} / \mathrm{cm}^{3}\right)\end{array}$ \\
\hline $1954-1985$ & 2.0 & - & 2.0 & - \\
$1985-1991$ & 2.0 & 2.0 & 2.0 & 1.0 \\
$1991-2002$ & 1.0 & 0.5 & 0.5 & 0.2 \\
$2003-2005$ & 1.0 & 0.2 & 0.5 & 0.2 \\
$2005-$ & & dust containing asbestos: fibres: $0.1 \mathrm{f} / \mathrm{cm}^{3}$, total dust: $0.5 \mathrm{mg} / \mathrm{m}^{3}$ & \\
\hline
\end{tabular}


methods, involving air sampling through membrane filters, is employed to determine the numerical data on fibre concentration. The concentration of respirable asbestos fibres in the air is determined by standardized microscopic method using phase contrast microscope at 600-times magnification. The limit of quantification (LOQ) of this method is at least 0.016 fibres in $1 \mathrm{~cm}^{3}$ air.

In some asbestos-cement plants that started operating in 1960s and 1970s, high asbestos dust concentrations were recorded until late 1980s; unfortunately, the relevant values were then expressed only as $\mathrm{mg} / \mathrm{m}^{3}$. It may be assumed that during the period when dry processing was used, fibre concentrations could be as high as a dozen or even several dozen fibres in $1 \mathrm{~cm}^{3}$ air. The introduction of wet processing has considerably reduced workplace dust concentrations. However, even as recently as in 1990, asbestos dust concentrations of $8 \mathrm{f} / \mathrm{cm}^{3}$ could be recorded at asbestos milling and delivery units. The transportation of asbestos as the raw material and the initial processing (defibration), which are associated with high fibre concentrations in ambient air, posed a major occupational hygiene problem. The imported asbestos was frequently supplied in damaged packages; the spillage causing an additional environmental pollution. The implementation of an automatic system of asbestos supply made it possible to keep the workplace concentrations of chrysotile within the MAC value of $0.5 \mathrm{f} / \mathrm{cm}^{3}$. This limit was binding till June 2003. The highest concentration of asbestos fibres $\left(0.86 \mathrm{f} / \mathrm{cm}^{3}\right)$ was observed in the production dept. of textile plants. A lower level $\left(0.47 \mathrm{f} / \mathrm{cm}^{3}\right)$ was noted in the friction materials dept. and the lowest one $\left(0.33 \mathrm{f} / \mathrm{cm}^{3}\right)$ in the gasket plant [4].

Today's occupational exposure to asbestos in Poland concerns workers involved in the maintenance and removal of asbestos-containing materials. Recently, the works comprising demolition of asbestos-cement products, their transportation and disposal at landfills have been intensified. Studies on asbestos fibre concentration in the breathing zone of workers employed at removal of various types of asbestos cement goods indicated low concentration levels ranging from $0.001 \mathrm{f} / \mathrm{cm}^{3}$ to $0.080 \mathrm{f} / \mathrm{cm}^{3}$. However, these results should be approached cautiously as the studies covered only the workers of the leading and perfectly operating companies with relevant technical equipment [5].

According to current legislation, in the case of exposure to asbestos dust, the concentration measurements should be performed at least once every three months. When the results of two consecutive measurements do not exceed 0.5 of the MAC value, the frequency of measurements can be reduced to at least once every six months [6]. Before the AMIANTUS Programme was launched (2001), no register of workers occupationally exposed to asbestos dust had been compiled in Poland. Based on the data collected from factory archives and regional divisions of the State Sanitary Inspectorate, the number of workers at asbestos processing plants has been estimated to be about 33 000. Considering other sectors of the national economy (insulation works, building industry, car repair shops, shipbuilding industry, etc.), the number of workers with intermittent exposure to asbestos dust from the use of asbestos-containing products is estimated to be ca. 150000 , and $30 \%$ of this population had been exposed in the past to concentrations that exceeded the then valid MAC values.

\section{HEALTH CARE FOR ASBESTOS WORKERS}

The health protection of workers exposed to asbestos dust is ensured by the provisions of EU directives and ILO conventions $[7,8]$. By virtue of these regulations, the Member State is committed to specify the measures to be taken to prevent and control health hazards related to occupational exposure to asbestos and to protect workers from such hazards. Compulsory prophylactic examinations of 
workers occupationally exposed to asbestos are one of the instruments used to meet these requirements [9].

In Poland, the Labour Code [10] makes it obligatory for both the employer and employee to arrange for the prophylactic examinations of workers, especially those working under hazardous conditions. As regards asbestos exposure, the health care covers the current and former workers exposed to asbestos. Providing prophylactic health care for workers is the responsibility of the occupational health services.

For workers occupationally exposed to asbestos, a chest radiograph (ILO classification) is performed as baseline. Medical examination includes evaluation of exposure, respiratory symptoms history, physical examination and spirometry. Prophylactic activities comprise pre-placement examinations and periodic examinations: the first periodic examination after three years of work, later on every two years, and after 10 years of work - every year. The responsible physician determines the frequency of prophylactic examinations, taking account of the worker's health condition, job description, exposure level, duration of employment and latency period for asbestos-related diseases.

\section{THE AMIANTUS PROGRAMME}

Subject to special protection are the former workers of all asbestos-processing plants in Poland listed in the Act on the Ban of Use of Asbestos-Containing Products of 19th June 1997 [11]. The Act specifies the following rights of the workers employed in these factories: free access to periodical medical examinations, free access to medications used to manage asbestos-induced diseases, once a year referral to a health-resort and exemption from treatment charges. The funds necessary to cover the costs incurred by these activities are allocated in the state budget.

To facilitate implementation of the Asbestos Ban Act, the Ministry of Health has launched the AMIANTUS
Programme of prophylactic examinations designated for former workers of asbestos processing plants. As envisaged in the Programme, each person who had been employed under conditions of occupational exposure in these plants was provided with a medical check-up book. The book contains information about the work post, the level and duration of exposure and the consecutive prophylactic examinations.

In view of the fact that the asbestos-processing plants were scattered all over Poland, the medical examinations for asbestos workers involve many different health care units. Thus, it was necessary to coordinate the examinations conducted by several dozen physicians from 13 occupational health care units.

The main tasks of the coordination of the Programme are as follows:

- to implement a uniform methodology of medical examinations,

- to ensure training and consultations,

- to monitor respiratory effects of exposure in workers occupationally exposed to asbestos dust,

- to keep a central register of workers exposed to asbestos,

- to manage database of results of prophylactic examinations.

The strategy of prophylactic examinations for asbestos workers has been developed by the Nofer Institute of Occupational Medicine in Lódź which also supervises the examinations of former workers of asbestos processing plants [12].

For the purposes of the AMIANTUS Programme, a unified procedure for large-scale prophylactic examinations has been adopted, and standardized forms to document medical records that would cover exposure assessment, as well as the principles of collecting occupational exposure data, have been prepared. All health centres performing the examinations follow the provisions of the 1997 Helsinki Criteria for diagnosis and attribution in asbestos-related 
diseases — for clinical, radiological, spirometric, histological diagnoses and exposure assessment [13-16].

The Programme tasks completed in 2000-2010 have made it possible to develop a database containing medical data on 6853 asbestos workers. The data derive from 18955 medical examinations performed in the course of the programme. Asbestosis was diagnosed in 1476 cases, i.e., $21.5 \%$ of the examined workers, lung cancer in 68 cases and mesothelioma in 40 cases.

Among the workers formerly exposed to asbestos dust who are subject to prophylactic examinations, a continuous yearto-year growth was noted in the proportion of pathological findings in radiological examinations (pleural alterations and parenchymal opacities). Also the number of patients with diagnosed asbestosis was found to increase from $7 \%$ in 2000 to $26 \%$ in 2010 [17]. This considerable increase is largely due to a better asbestos-related disease detectability achieved by virtue of the implemented Programme.

\section{ASBESTOS-RELATED OCCUPATIONAL DISEASES}

The procedure for diagnosing and medical certification of occupational diseases and the list of occupational diseases are specified in current regulations. The procedure comprises three stages: (1) Reporting a suspected occupational disease; (2) Diagnosis and medical certification of occupational disease; and (3) Administrative decision whether or not the case can be regarded as an occupational disease.

According to these regulations, the reporting of a suspected case of occupational disease may concern a current or former worker. The case should be reported to relevant sanitary inspector and labour inspector, depending on workplace location. The case can be reported by the employer or an occupational physician.

The legislation specifies the institutions with the first- and second-level capacity for certifying occupational diseases as well as the qualification requirements for a physician to be authorised to issue medical certification. The first-level units are the clinics of occupational diseases in regional occupational health centres and in-patient clinics at medical universities. The second-level institutions include research and development units in the field of occupational medicine. Once the decision has been made that a given case can or cannot be diagnosed as an occupational disease, it is forwarded to the State Sanitary Inspectorate (SSI), the employer and the worker in whom the occupational disease was suspected.

An employee who does not agree with the decision issued may appeal to the SSI and apply for a new examination to be performed by a second-level certifying institution. When the procedure for medical certification is completed, a competent State Sanitary Inspector issues a decision that a given case can or cannot be deemed an occupational disease. This decision can be appealed to the Administrative Court [18].

Every certified case of occupational disease is registered, and information on the case, on a special form, is forwarded by the local sanitary inspector to the Central Register of Occupational Diseases located at the Nofer Institute of Occupational Medicine in Łódź.

The current list of occupational diseases includes asbestosis, diffuse thickening of pleura or pericardium, diffuse plaques of pleura or pericardium, pleural exudate, chronic obstructive bronchitis, and lung cancer, as well as pleural and peritoneal mesothelioma as the pathologies caused by exposure to asbestos.

Over the period of 1976-2010 in Poland, 4253 cases of diseases were recorded as deriving from occupational exposure to asbestos dust. The most prevalent were asbestosis (64\%), lung cancer (12.2\%), diseases of pleura (9.7\%) and pleural mesothelioma (6.4\%). The growing tendency in the number of cases of occupational asbestos-related diseases and asbestos-related pathologies is presented in Table 2. The exceptions from the general tendency are 'other non-malignant diseases' and 'other neoplasms', 
Table 2. Asbestos-related occupational diseases recorded in Poland in 1976-2010

\begin{tabular}{|c|c|c|c|c|c|c|c|}
\hline \multirow[b]{2}{*}{ Period } & \multicolumn{7}{|c|}{$\begin{array}{l}\text { Cases } \\
(\mathrm{n})\end{array}$} \\
\hline & asbestosis & lung cancer & $\begin{array}{c}\text { pleural } \\
\text { mesothelioma }\end{array}$ & $\begin{array}{c}\text { diseases of } \\
\text { pleura or } \\
\text { pericardium* }\end{array}$ & other neoplasms & $\begin{array}{l}\text { other non- } \\
\text { malignant } \\
\text { diseases }\end{array}$ & total \\
\hline 1976-1980 & 106 & 4 & 2 & - & 1 & - & 113 \\
\hline 1981-1990 & 771 & 54 & 15 & - & 29 & 13 & 882 \\
\hline 1991-2000 & 702 & 173 & 69 & - & 82 & 54 & 1080 \\
\hline 2001-2010 & 1222 & 306 & 193 & 427 & 18 & 12 & 2178 \\
\hline Total & 2801 & 537 & 279 & 427 & 130 & 79 & 4253 \\
\hline
\end{tabular}

* Listed among occupational diseases since 2002.

which is associated with the changing over time contents of the list of occupational diseases as well as the new regulations concerning the cause-effect relationship between asbestos exposure and 'other diseases'.

\section{Asbestosis}

Asbestosis, or interstitial pulmonary fibrosis, constitutes the main occupational disease diagnosed among workers exposed to asbestos dust. The first cases of asbestosis were registered in 1970s. The remarkable growth in the number of cases recorded in 1981-1983

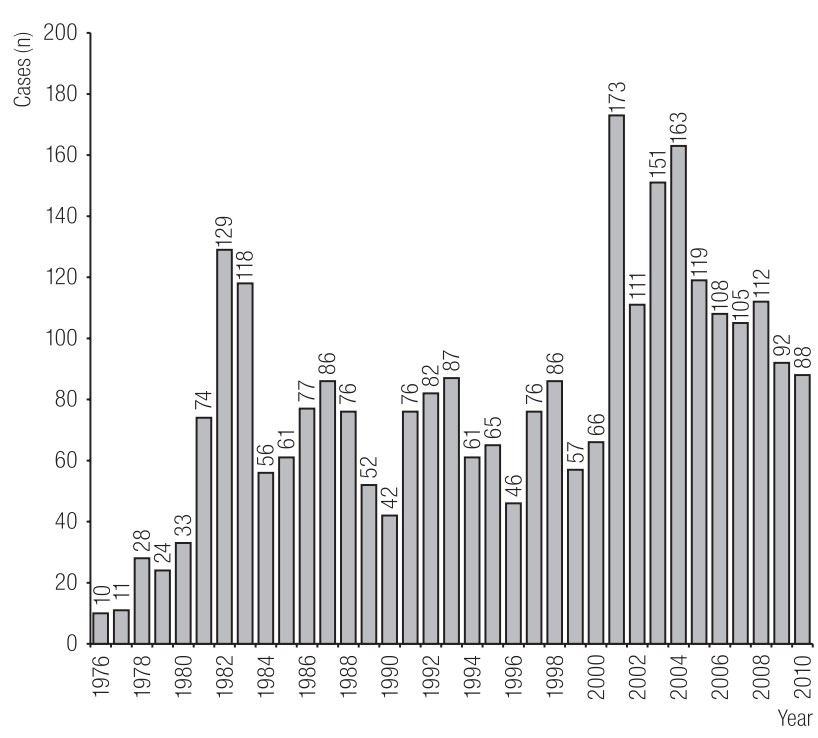

Fig. 1. Asbestosis in Poland in 1976-2010. was attributable to increased detectability of new cases thanks to the clinical examinations of asbestos workers (Figure 1). The examinations were carried out under research projects conducted by the institutes of occupational medicine in selected asbestos-processing plants. Likewise, the increased number of cases diagnosed since 2001 is linked to the implementation of the AMIANTUS Programme for prophylactic examinations of former asbestos workers.

\section{Pleural mesothelioma}

According to official statistics, pleural mesothelioma is a rather rare type of cancer in Poland. With the rate of about 6 cases per 1 million people, Poland is classified among the countries with a low incidence of this disease in the general population. However, since 1980, a slightly increasing incidence has been observed both among males and females. The first case of occupational pleural mesothelioma was noted in 1976. Over the period of 1976-2010, a total of 280 cases of pleural mesothelioma were classified to be of occupational origin. The cases recorded in 1980-1996 (when this disease was considered as a separate item in the national statistics) accounted for as little as $2.4 \%$ of the total cases of pleural mesothelioma diagnosed at that time in the general population $(3.2 \%$ in males, $1.5 \%$ in females). 
In Poland, this extremely low level of diagnosing pleural mesotheliomas with occupational background is an essential problem in the monitoring of health effects of occupational exposure to asbestos. For comparison, in other European countries and in Canada, the $40 \%$ rate of occupational mesotheliomas that can be claimed for compensation is considered a gross underestimation [19-21].

The major factor accounting for the underrated occupational fraction of mesothelioma is an insufficient knowledge among clinicians on the occupational aetiology of this neoplasm, and hence their failure to perform a detailed interview about the patient's work history. The age of the workers when diagnosed with pleural mesothelioma due to occupational exposure to asbestos was evidently lower than the age of individuals with this neoplasm in the general population.

A number of factors need to be taken into account when one considers the relatively low total number of mesotheliomas in the general population, as well as of the occupational mesotheliomas. These include:

- difficulties in diagnosing this rare cancer;

- long period of latency (up to 40 years) for mesothelioma. The large industrial plants processing considerable quantities of crocidolite started operating in 1960s-1970s; therefore, the presently recorded increase in the number of deaths from pleural mesothelioma may be due to this long latency;

- low cumulative dose of asbestos dust due to short periods of employment: a high proportion of asbestos workers were employed for a short time;

- small number of workers employed at workplaces with high asbestos dust concentrations.

\section{Lung cancer}

Some of the hypothetical causes of the relatively low number of pleural mesotheliomas in Poland, including those of occupational aetiology, refer also to asbestos-related

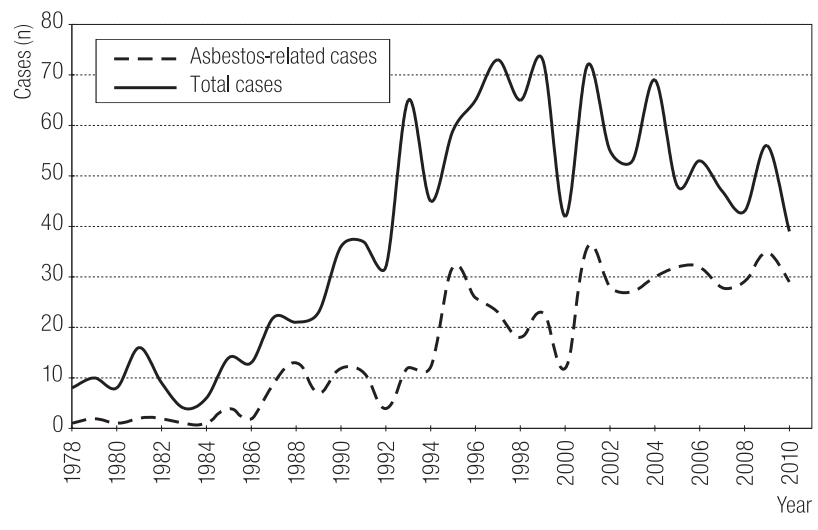

Fig. 2. Total registered cases of occupational lung cancer vs. asbestos-related lung cancer in Poland, 1978-2010.

lung cancers. The first case of lung cancer attributed to occupational exposure to asbestos dust was recorded in 1978. Despite the low number of the diagnosed cases of occupational asbestos-related lung cancer, they accounted for as much as $40 \%$ of the total cases of occupational lung cancer recorded in 1978-2010 (Figure 2). It should be noted that in Poland, every case of lung cancer with documented exposure to asbestos is compensated as an occupational disease, no matter whether asbestosis had been diagnosed beforehand, and irrespective of the smoking habit.

\section{Compensation for occupational asbestos-related diseases} The basis for claiming compensation for an occupational disease is a legally binding administrative decision confirming the occupational etiology of the disease. The decision is made by the State Sanitary Inspector based on medical certification, epidemiologic surveillance of work environment and occupational exposure data. The types of compensation, the procedures for granting them, calculating the amount due and determining the mode of payment are regulated separately [11,22-24].

It should be stressed that it is the health consequences of the disease rather than the presence of the occupational disease itself that is compensated for. Indemnity benefits connected with an occupational disease are paid by the 
Social Insurance Agency (ZUS) from the Social Insurance Fund. The social insurance benefits pertaining to occupational asbestos-related diseases include:

- sickness benefit - for the insured worker whose temporary disability for work of up to 182 days is a consequence of an occupational disease,

- rehabilitation benefit - for the insured worker who after a period of receiving sickness benefits has remained incapable for work but who is likely to regain work ability provided that the treatment or rehabilitation is continued; the maximum period of receiving this benefit is 12 months;

- top-up benefit - for the insured worker whose earnings have decreased due to permanent or long-term health impairment; the top-up benefit is due to the period of rehabilitation, but no longer than for 24 months $[22,23]$.

Determining the degree of health impairment and whether the death of the insured worker has been related to an occupational disease is the responsibility of a physician dealing with medical certifications for the Social Insurance Agency. He/she is also obliged to find out whether the worker's disability for work, making him/her eligible for disability pension, has been the consequence of an occupational disease. When certifying permanent or longterm health impairment related to occupational disease, the physician has to refer to the decision of the State Sanitary Inspectorate confirming the occupational etiology of the disease.

Permanent damage to health is a reduction in the efficiency of the organism that causes impairment of the body which has little chance of improvement. Long-term damage to health is a reduction in the efficiency of the organism that causes impairment of the body for a period exceeding six months, which can improve. The worker who has a permanent or long-term damage to health or has become incapable for work as a consequence of an occupational disease is entitled to receive:
- one-time indemnity — for the insured worker who has experienced a permanent or long-term health impairment,

- work disability pension - for the insured who has become unable to work due to occupational disease,

- vocational training pension - for the insured worker who is unable to continue employment in his profession as a consequence of an occupational disease,

- nursing allowance - for the person eligible for pension, deemed completely incapable of work or independent existence, or who has reached the age of 75 ,

- medical costs reimbursement - of dental treatment and preventive vaccinations, as well as providing orthopedic care measures within the scope stipulated by the law.

The family members of the worker who has died from an occupational disease are also entitled to one-time compensation. They also receive the family pension and supplement to survivor's pension [23].

The degree of health impairment is determined from the effects on particular body organs or systems, and expressed as percentage, in accordance with the reference criteria for the assessment of permanent or long-term health impairments [24]. For asbestos-related diseases, the degree of health impairment can range from 10 to $100 \%$.

The assessment of the degree of health impairment and its relation to occupational disease should be made after the treatment and rehabilitation have been completed. A lump-sum work injury compensation is calculated, based on average gross earnings in the national economy, for each percent of the permanent or long-term health impairment. The amount of average gross monthly earnings is published by the president of the Central Statistical Office in the Journal of Laws, while the amounts of one-time compensations related to occupational diseases are published as announcements by the Minister of Labour and Social Policy. 
Apart from the benefits specified above, the former asbestos workers are eligible for additional benefits which include free-of-charge medications to manage asbestosrelated diseases and free-of-charge health resort treatment once a year [11].

\section{GOVERNMENT PROGRAMME ON ASBESTOS ELIMINATION IN POLAND}

On 14 July 2009, the Council of Ministers, requested by the Ministry of Economy, passed a resolution approving the foundation of the "Programme to Free the Country from Asbestos in the years 2009-2032". The programme is a continuation and updating of a previous long-term programme on "Elimination of asbestos and asbestos-containing products used in Poland, 2002-2032". It maintains the existing targets and formulates new tasks necessary to eliminate asbestos as well as protect the workers contracted to perform demolition works. Those workers will constitute the exposed group who need prophylactic health care. The main objectives of the Programme are removal and disposal of asbestos-containing products for minimizing the adverse health effects caused by asbestos. It should be stressed that according to current legislation, the asbestos-containing materials to be removed are considered hazardous waste and as such are subject to specific regulations. The Programme objectives will be pursued gradually until 2032, when Poland is expected to be an asbestos-free country ${ }^{1}$. To achieve the long-term objectives and considering the interdisciplinary character of the programme, it is essential to coordinate the activity of all organizations and institutions involved and establish cooperation with the state administration, local authorities, state inspectorates and social partners. Therefore, the Programme tasks are designed to be carried out at the three following levels:

\footnotetext{
${ }^{1}$ The body responsible for the Programme coordination and monitoring is the Minister of Economy (http://www.mg.gov.pl).
}

- central level — the Cabinet, the Minister of Economy, and within the ministry, the Principal Coordinator of the Programme,

- district level - district administration and self-governments,

- local level - community and municipality administration, self-governments.

The implementation of the Programme and its future success depend on the discipline in performing individual tasks, the involvement of government bodies, as well as on social activities related to safe disposal of asbestos-containing products. The Programme objectives comprise, among other things, withdrawing asbestos from different industrial branches, especially the construction industry; developing guidelines on the storage of asbestos wastes (landfills); and identifying the possible sources of funding, such as the national budget, environmental protection funds, European Union projects and local government resources. They also include preparing guidelines on how to develop local programmes for elimination of asbestos products as well as on the management and monitoring of the programme activities.

One of the tasks described in the Programme was to establish a centre for research on the impact of asbestos exposure on human health. In 2004, The Reference Centre for Asbestos Exposure and Health Risk Assessment was established at the Nofer Institute of Occupational Medicine in Łódź. The Centre activities cover research activities and analysis for the government Programme, organization of specialized training in asbestos-related health hazards, and providing expertise, information and dissemination of knowledge about health effects and health risks associated with occupational and environmental exposure, and the safety of work with asbestos.

The present report on asbestos as an occupational health problem provides grounds for developing the National Programme for Elimination of Asbestos-related Diseases. The framework for such an activity has been an outcome of ILO and WHO cooperation [25]. 


\section{REFERENCES}

1. Szeszenia-Dąbrowska N, editor. Asbestos. Occupational and Environmental Exposure. Effects and Prophylaxis. Łódź: Nofer Institute of Occupational Medicine; 2004 [in Polish].

2. Government Programme to Free the Country from asbestos in the years 2009-2032 (updating of the Programme "Elimination of asbestos and asbestos-containing products used in Poland, 2002-2032”) [cited 2011 Feb 1]. Available from URL: http://www.mg.gov.pl/Gospodarka/Azbest/Program+oczyszczania+kraju+z+azbestu [in Polish].

3. Stroszejn-Mrowca G, Więcek E. Evaluation of exposure of workers to asbestos dust in asbestos processing plants. Arch Immunol Ther Exp 1982:263-8 [in Polish].

4. Stroszejn-Mrowca G, Szczepaniak M, Więcek E. Occupational exposure to dust containing asbestos in factories producing and using asbestos products in the years 1986-1989. Med Pr 1991;42(5):343-5 [in Polish].

5. Stroszejn-Mrowca G, Szadkowska-Stańczyk I. Monitoring of environmental and occupational exposure to asbestos dust during removal of "asbestos products" from environment. In: Dyczek J, editor. Proceedings of the International Seminar on Asbestos Risk Reduction and Measurement of Asbestos Fibre Concentration. 2006 Sept 28-29, Kraków, Poland. Kraków: AGH; 2006. p. 21-4.

6. Regulation of the Minister of Health of 2 February 2011 on the tests and measurements of agents harmful to health in work environment. J Laws 2011, No. 33, item 166 (Dec 16, 2011) [in Polish].

7. Directive 2009/148/EC of the European Parliament and of the Council of 30 November 2009 on the protection of workers from the risks related to exposure to asbestos at work. Off J EU 2009;L330:16.

8. International Labor Organization. Convention concerning safety in use of asbestos (No 162). Geneva: ILO; 1986.

9. Regulation of the Minister of Health and Social Welfare of 30 May 1996 on the performance of prophylactic medical examinations among workers, the range of preventive health care for workers, and medical certifications issued for purposes specified in the Labor Code. J Laws 1996; No. 69, item 332 as amended (Jun 25, 1996) [in Polish].
10. The Act of 26 June 1974. Labor Code (unified text). J Laws 1998, No. 21, item 94 as amended (Dec 23, 1997) [in Polish].

11. The Act of 19 June 1997 on the ban of the use of asbestos-containing products (unified text). J Laws 2004, No. 3, item 20 as amended (Jan 12, 2004) [in Polish].

12. Szeszenia-Dąbrowska N, Szubert Z. Prophylactic examinations of former workers at asbestos processing plants: The AMIANTUS Project. Med Pr 2002;53(6):451-6 [in Polish].

13. Tossavainen A. Asbestos, asbestosis, and cancer: the Helsinki criteria for diagnosis and attribution. Scand J Work Environ Health 1997;23:311-6.

14. International Labour Office. Guidelines for the use of ILO International Classification of Radiographs of Pneumoconioses. Geneva: ILO; 1980.

15. Hillerdal G. Criteria for clinical diagnosis: Lung function and symptoms. Asbestos, Asbestosis and Cancer. Proceedings of an International Expert Meeting; 1997 Jan 20-22; Helsinki: Finnish Institute of Occupational Health; 1997. p. 46-9.

16. Hillerdal G. Radiological criteria: Pleural changes. Asbestos, Asbestosis and Cancer. Proceedings of an International Expert Meeting; 1997 Jan 20-22; Helsinki: Finnish Institute of Occupational Health; 1997. p. 41-5.

17. AMIANTUS Programme. Annual Report [unpublished]. Łódź: Nofer Institute of Occupational Medicine; 2000-2010 [in Polish].

18. Regulation of the Council of Ministers of 30 June 2009 on occupational diseases. J Laws 2009, No. 105, item 869 (Jun 30, 2009) [in Polish].

19. Dano H, Skov T, Lynge E. Underreporting of occupational cancers in Denmark. Scand J Work Environ Health 1996;22: $55-7$.

20. Andersson E, Toren K. Pleural mesotheliomas are underreported as occupational cancer in Sweden. Am J Ind Med 1995;27:577-80.

21. Cree MW, Lalji M, Jiang B, Carriere KC. Underreporting of compensable mesothelioma in Alberta. Am J Ind Med 2009;52(7):526-33. 
22. The Act of 25 June 1999 on financial benefits from social insurance in the situation of sickness and maternity (unified text). J Laws 2010, No. 77, item 512 as amended (May 22, 2010) [in Polish].

23. The Act of 30 October 2002 on social insurance from accidents at work and occupational diseases (unified text). J Laws 2009, No. 167, item 1322 (Sep 22, 2009) [in Polish].

24. Regulation of the Minister of Labour and Social Policy of 18 December 2002, on the procedures for certification of permanent or long-term health impairment, determination of the degree of health impairment, and payment of compensation. J Laws 2002, No. 234, item 1974 (Dec 18, 2002) [in Polish]. 25. Report of the Committee ICOH/2003/D.4. Thirteenth Session of the Joint ILO/WHO Committee on Occupational Health; Geneva, 2003 Dec 9-12; Geneva: International Labour Office; 2006.

This work is available in Open Access model and licensed under a Creative Commons Attribution-NonCommercial 3.0 Poland License - http://creativecommons.org/ licenses/by-nc/3.0/pl/deed.en. 